\title{
Prontuário Médico e suas Implicações Médico-Legais na Rotina do Colo-Proctologista
}

\section{Medical Record and his Medical-Legal Involvement in Daily Procedures of Colon and Rectal Surgeon}

\author{
LUIZCARLOS L. PRESTES JR. ${ }^{1}$; MARY RANGEL ${ }^{2}$ \\ ${ }^{1}$ Ex-Chefe da Clínica de Proctologia do Hospital Naval Marcílio Dias; Coordenador da Câmara Técnica de Medicina \\ Legal do Conselho Regional de Medicina do Estado do Rio de Janeiro; Perito Judicial e Legista; ${ }^{2}$ Doutora em \\ Educação com Pós-Doutorado na área de Psicologia Social; Professora de Didática da Universidade Federal \\ Fluminense; Titular da área de ensino-aprendizagem da Universidade do Estado do Rio de Janeiro.
}

PRESTES JR. LCL; RANGEL M. Prontuário Médico e suas Implicações Médico-Legais na Rotina do Colo-Proctologista. Rev bras Coloproct, 2007;27(2): 154-157.

RESUMO: As normas do Conselho Federal de Medicina preceituam que o médico não poderá deixar de preencher corretamente o prontuário médico. Essa observância é fundamental, pois sendo o atendimento prestado ao paciente uma ação multidisciplinar, todos os envolvidos ficarão informados sobre as condições clínicas, evolução, resultados de exames e procedimentos realizados nos pacientes. Sob o ponto de vista legal é um precioso instrumento, talvez o mais importante, em demandas judiciais, pois é a partir de sua análise que os peritos e julgadores colhem subsídios para a decisão judicial. Sob o ponto de vista de saúde pública, são nos prontuários médicos que residem os dados, permitindo os dados de prevalências e de incidências de determinadas doenças, permitindo assim, ações de prevenção e medidas de tratamento mais eficazes. Este trabalho tem como objetivo enfatizar a importância do cumprimento das normas e do correto preenchimento do prontuário médico, ressaltando suas implicações médico-legais, principalmente na prática da cirurgia colo-retal. Tais práticas não só representam a qualidade do trabalho profissional, mas permitem aos médicos dispor de um importante instrumento de defesa nas ações judiciais.

Descritores: Ficha médica; prontuário; boletim médico; implicações forenses.

O ensino médico, hoje, desenvolvido no nosso país, focaliza primordialmente os aspectos técnicos que dizem respeito à prática médica. A estrutura curricular pouco enfoca ao profissional que estará, em breve no mercado de trabalho, os aspectos que abordam o relacionamento com o paciente, o despertar para fiel observância do código de ética médica e, conseqüentemente, a prevenção quanto a possíveis demandas judiciais, que tanto têm preocupado a classe médica.

Dentre os inúmeros fatores envolvidos na análise médico-legal do exercício profissional, na suspeita do chamado "erro médico", destacamos o prontuário médico, acervo documental de extrema relevância que traduz o relacionamento entre o paciente e a equipe de saúde.

A rotina incansável dos colo-proctologistas e cirurgiões entre hospitais, clínicas e estabelecimentos de saúde, faz com que o profissional não perceba a importância médico-legal de que se reveste o correto preenchimento do prontuário médico.

Inicialmente, como definição, podemos conceituar o prontuário médico como o acervo documental do paciente, organizado e conciso, referente ao registro dos cuidados médicos prestados, assim como todos as informações, exames, procedimentos e quaisquer documentos pertinentes a essa assistência.

Trabalho realizado na Universidade do Estado do Rio de Janeiro (UERJ).

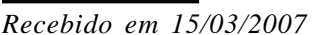

Aceito para publicação em 07/05/2007 
Vale lembrar que, conforme preceitua, o art. 69 do Código de Ética Médica, a documentação dos atos médicos é parte relevante da prática médica.

Em tal documentação deve constar a anamnese, o exame clínico, a prescrição terapêutica, os relatórios de enfermagem e de outros serviços, descrição de cirurgias, ficha anestésica, exames de qualquer natureza, e ainda deve ser minuciosa na descrição das circunstâncias em que os mesmos foram realizados.

O prontuário médico pertence ao paciente, sob a guarda e responsabilidade dos médicos e das instituições de saúde.

Portanto, é um valioso instrumento de:

a) Assistência Médica: a correta organização, com dados evolutivos cronológicos com fácil manipulação e consulta permite uma visão global do estado clínico do paciente, além de permitir a comunicação entre as diversas equipes de saúde.

b) Ensino: é, na verdade, o instrumento utilizado para a discussão de casos. As diversas situações clínicas só poderão ser recompostas com um prontuário adequadamente preenchido.

c) Pesquisa científica: Todos os dados são importantes e, portanto, devem ser preenchidos, pois não se sabe quais os dados que serão úteis para uma pesquisa futura.

d) Controle de qualidade: é um exemplo de gerenciamento das atividades médico-hospitalares e ainda prevista na Resolução 41/92 do Conselho Regional de Medicina que tornou obrigatória a Comissão de Revisão de Prontuários nas instituições de saúde.

e) Controle de custos: também é dependente da veracidade e detalhamento das informações contidas no prontuário médico.

A difícil tarefa da demonstração do suposto erro médico encontra na prova documental um respaldo importante, tendo em vista que os julgadores, na maioria das vezes, alicerçam sua decisão baseada em elementos de caráter documental.

Não existe peça técnica que possa reproduzir melhor todas as circunstâncias que envolvem o atendimento ao paciente, do que o prontuário médico. Nele são descritos o horário e dose da medicação, todos os sintomas, reações, procedimentos e cirurgias realizadas, revelando com precisão as condutas adotadas e permitindo com isso, a avaliação dos prestadores de serviço.

Em meio aos direitos do paciente está o dever de ser informado sobre o estado de saúde que se encontra, inclusive por escrito, se assim for solicitado. $\mathrm{O}$ colo-proctologista, portanto tem o dever legal de informação, e para tal, na grande maioria das vezes, o faz tomando por base as informações contidas no prontuário médico.

Na rotina diária em Colo-Proctologia, particularmente, temos o dilema de informar ao paciente a possibilidade de realizarmos uma ostomia seja temporária ou definitiva, mas tal informação é primordial e o paciente deverá sempre estar envolvido nessa decisão. Tudo o que for tratado ou decidido com o paciente e seus familiares, deverá constar no seu prontuário médico.

Por sua vez, as Instituições de Saúde têm por dever a manutenção do prontuário atualizado e sob sua guarda, pronto a qualquer momento para consulta, ou por intermédio de pleito judicial ser enviada a cópia fiel ao juízo provocado, servindo como elemento indispensável da prova pericial. A avaliação da atuação da equipe de saúde poderá ser percebida através das informações contidas no prontuário, e deve sempre corresponder aos preceitos éticos e cientificamente corretos.

Com a introdução do Novo Código Civil, em vigor desde 2003, se o fato gerador da ação judicial ocorreu após 11/01/2003, o prazo de prescrição da ação proposta passa a ser de 03 anos ${ }^{1}$.

Com isso teoricamente, o prazo de arquivamento passou também para 3 anos. No entanto, o prazo anteriormente estipulado, de 20 anos, deve ser obedecido, caso os fatos geradores tenham ocorrido nos últimos 20 anos.

Não é raro verificar discrepâncias entre os procedimentos relatados, e o que foi efetivamente realizado. Não menos raras ainda as rasuras, as letras absurdamente ilegíveis e, principalmente, a omissão de informações.

Existem situações em que a prática médica demonstra uma maior ocorrência de falhas no preenchimento do prontuário médico. São aquelas que envolvem o atendimento de emergência nos grandes hospitais. Poderíamos considerar que a agitação, as rápidas decisões e o próprio ambiente dos setores de emergência podem propiciar omissões, que seguramente irão ser questionadas numa futura demanda judicial. Vale ressaltar também as cirurgias de emergência, com as suas características de múltiplos procedimentos, sempre voltados para as-

(1) Artigo 206 § 3, inciso V do Novo Código Civil. 
segurar a manutenção da vida nas diversas situações de risco. Neste caso a detalhada descrição do ato cirúrgico, com todas as lesões encontradas, incluindo técnicas e táticas empregadas irá assegurar, documentalmente, a correta realização da manobras cirúrgicas, principalmente se as complicações surgirem no pós-operatório.

As cópias dos boletins de atendimento médico de vítimas de lesões violentas, com absoluta certeza, serão solicitados, através dos peritos, pelas autoridades policiais ou judiciárias e, portanto, serão esperadas descrições detalhadas das lesões, a história alegada pelo paciente, bem como todo o tratamento instituído e o destino do mesmo. A letra legível dos profissionais envolvidos nesse atendimento é condição fundamental para um perfeito entendimento de tudo que foi realizado.

A produção da prova pericial com a nomeação de um perito médico pela autoridade judiciária é um procedimento quase rotineiro, quando a conduta técnica deva ser avaliada. A prática forense demonstra que o paciente vítima de um suposto erro médico, sendo hiposuficiente nos seus conhecimentos de medicina, não reúne condições para apresentar as devidas provas.

O julgador, invertendo o ônus da prova, incumbe ao médico, acusado de danos ao paciente, provar que agiu dentro dos parâmetros científicos, éticos e sob o prisma técnico-profissional para aquela situação.

Para que o médico reúna as provas técnicas necessárias à sua defesa, não há elemento de tamanha relevância do que o prontuário médico. E não basta que a descrição dos procedimentos esteja correta, fazse mister que constem também as autorizações, consentimentos e a plena ciência dos fatos, obtidas junto ao paciente ou ao seu representante legal.

Vale ressaltar que diante das inúmeras disputas judiciais envolvendo médicos, hospitais e pacientes a prudência na relação médico-paciente e a correta escrituração do prontuário médico podem ser consideradas as vigas mestras que norteiam tais demandas.

Não se justifica, hoje, a desinformação acerca da importância do prontuário para os profissionais de saúde, mormente quando o paciente está sob o cuidado de uma equipe multidisciplinar.

A responsabilidade do Diretor Técnico na análise da atuação das Comissões de Revisão de Prontuários, norma legal instituída pelos Conselhos de Medicina, vem permitindo um controle mais eficaz na quali- dade dos prontuários médicos, principalmente nos Hospitais Universitários em que a prática correta é um elemento de formação profissional.

A evolução tecnológica, principalmente com a informatização de Hospitais, permitiu o desenvolvimento de novos métodos de armazenamento de dados na área médica.

Hoje, o prontuário médico informatizado já é uma realidade sendo utilizado, rotineiramente, em muitas instituições de saúde do país. Entretanto, sua validade, no conjunto probatório, em demandas judiciais, ainda tem sido questionada no meio jurídico.

Com o objetivo de dirimir as dúvidas geradas pela controvérsia do assunto, o Conselho Federal de Medicina expediu a Resolução 1639/2002, que aprovou as "Normas Técnicas para o uso de Sistemas Informatizados para a Guarda e Manuseio do Prontuário Médico". Tal documento norteia a utilização do prontuário informatizado, desde que o sistema utilizado assegure o sigilo profissional, a inviolabilidade do sistema e a recuperabilidade dos dados. O Conselho Federal de Medicina ainda dispõe, para os interessados, uma análise técnica do sistema e uma certificação, o que, certamente, permite uma maior credibilidade como prova judicial.

Vale ressaltar ainda, que numa sociedade moderna em que a qualidade dos sistemas de saúde é posta à prova constantemente, um prontuário médico bem confeccionado traduz, não somente a seriedade dos profissionais envolvidos, mas também um verdadeiro instrumento de defesa judicial. As freqüentes ações de responsabilidade civil, envolvendo médicos e hospitais, têm no prontuário médico todo o repertório técnico e as ações empreendidas pelos profissionais.

As chefias de clínica e de serviços, os diretores técnicos e as assessorias jurídicas das Instituições de Saúde têm um papel fundamental na divulgação da importância de uma correta escrituração dos prontuários médicos. Já os programas de residência médica em Colo-Proctologia, principalmente, desenvolvidos nos Hospitais Universitários se beneficiariam muito, na formação desses profissionais, ressaltando em palestras, mesas redondas e atividades didáticas a importância do tema envolvendo a responsabilidade civil do médico.

A Sociedade Brasileira de Colo-Proctologia vem também envidando esforços para divulgar nos Congressos, por meio de conferências e mesas re- 
dondas temas de defesa profissional e direito médico.

A Comissão de Revisão de Prontuários, instituída pelos Conselhos Regionais de Medicina, já vem exercendo um papel relevante no aprimoramento técnico dos profissionais quanto ao correto preenchimento do prontuário médico. Entretanto, essa divulgação deveria ser estendida já nos cursos de graduação, onde os estudantes já começariam a se deter nas particularidades médico-legais que envolvem essa documentação.

Uma medida altamente salutar seria a abordagem de temas de Direito Médico nos cursos de Gradu- ação em Medicina que, de forma mais abrangente e completa, orientaria os futuros profissionais médicos, quanto às situações de ordem prática, ressaltando os aspectos jurídicos e éticos que envolvem o exercício profissional.

Portanto, a preocupação com a boa qualidade do prontuário médico deve fazer parte da rotina das instituições de saúde, mormente aquelas de cunho universitário, cujo papel de formação deve ser instituído de forma plena e de elevada categoria, a fim de atender aos anseios de uma sociedade cada vez mais exigente.

\begin{abstract}
The norms of Federal Council of Medicine set down that the doctor cannot stop filling out the medical handbook correctly. That observance is fundamental, because being the service rendered the patient an action to multi-discipline, all involved they will be them informed about the clinical conditions, evolution, results of exams and procedures accomplished in the patients. Under the legal point of view it is a precious instrument, maybe the most important, in judicial demands, because it is starting from his/her analysis that the experts and judges pick subsidies for the judicial decision. Under the point of view of public health they are in the medical handbooks that the data live, allowing the data of prevalences and of incidences certain diseases, allowing like this, prevention actions and more effective treatment measures. This work has as objective emphasizes the importance of the execution of the norms and of the correct completion of the medical handbook, emphasizing their forensic implications, main in the colon rectal surgery practice. Such practices not only they represent the quality of the professional work, but they allow to the doctors disposal of an important defense instrument in the lawsuits.
\end{abstract}

Key words: He/she annotates doctor, handbook, medical report, forensic implications.

\section{REFERÊNCIAS}

1. França, GV. Comentários ao Código de Ética Médica. Rio de Janeiro: Ed. Guanabara Koogan, 2002.

2. França,GV. Medicina Legal. Rio de Janeiro: Ed. Guanabara Koogan, 2001.

3. Moraes, IN. Erro Médico e a Justiça. São Paulo: Ed. Revista dos Tribunais, 2003.

4. Petroianu, A. Ética, Moral e Deontologia Médicas. Rio de Janeiro: Guanabara Koogan, 2000.

5. Sebastião, J. Responsabilidade médica civil, criminal e ética. Belo Horizonte: Ed. Del Rey, 2001.

6. Zamprogna, MF. Responsabilidade civil do médico. Porto Alegre: Ed. Sagra Luzzatto, 2001.
7. Nigre, AL. O atuar médico. Direitos e obrigações.Rio de Janeiro: Ed Noa, 2004.

8. Gomes, CJE. Responsabilidade das condutas médicas. Brasília: Ed. OAB, 2006.

9. Roberto, LMP. Responsabilidade Civil do Profissional de Saúde e Consentimento Informado.Curitiba: Ed. Juruá, 2006.

Endereço para correspondência:

LUIZ CARLOS LEAL PRESTES JUNIOR

Rua Siqueira Campos, 43 / sala 621 - Copacabana

CEP: 22031-070

Rio de Janeiro - RJ

Tel.: (21) 2547-2294 / 9987-7748

E-mail: luizprestes@bol.com.br 